\title{
PENGARUH PELATIHAN DAN BUDAYA ORGANISASIONAL TERHADAP KINERJA KARYAWAN DENGAN KEPUASAN KERJA SEBAGAI VARIABEL INTERVENING

\author{
(Survey Pada Departemen Sumber Daya Manusia Di Pt. Madubaru Pg/Ps Madukismo)
}

\author{
Fereshti Nurdiana Dihan', M. Rizky Pratama² \\ ${ }^{1}$ Fakultas Ekonomi, Universitas Islam Indonesia \\ fereshtideevadha@gmail.com \\ ${ }^{2}$ Fakultas Ekonomi, Universitas Islam Indonesia \\ emitamtam99@gmail.com
}

\begin{abstract}
This study discusses the effect of training and organizational culture on performance with job satisfaction as intervening variable. Respondents in this study were 73 employees in the human resources department at PT. MADUBARU PG / PS MADUKISMO. The purpose of this study is to determine the effect of training on employee performance partially, the influence of organizational culture on employee performance partially, the effect of training on job satisfaction partially, the influence of organizational culture on job satisfaction partially, the influence of job satisfaction on employee performance partially, to find out whether job satisfaction mediates the effect of training on employee performance, to find out whether job satisfaction mediates the influence of organizational culture on employee performance.

The results of this study show that partially there is a positive and significant influence between training on employee performance, partially there is a positive and significant influence between organizational culture on employee performance, partially there is a positive and significant influence between training and job satisfaction, partially there is a positive influence and significant between organizational culture to job satisfaction, partially there is a positive and significant influence between job satisfaction on employee performance. In this study also proved that job satisfaction mediate the effect of training on employee performance, job satisfaction mediate the influence of organizational culture on employee performance in the department of human resources PT. MADUBARU PG / PS MADUKISMO.
\end{abstract}

Keywords: Training, Organizational Culture, Job Satisfaction, Performance

(C) 2018 JBTI. All rights reserved

Article history : received 6 Jan 2018; revised 20 Jan 2018 ; accepted 25 Jan 2018

\section{PENDAHULUAN}

Faktor yang paling penting bagi organisasi dalam pencapaian tujuannya adalah sumber daya manusia, karena sebaik apapun sebuah organisasi, sebanyak apapun sarana serta prasarana yang dimiliki organisasi, tanpa adanya peran dari sumber daya manusia (pegawai) semua itu tidak akan berjalan dengan baik, karena SDM berperan sebagai motor penggerak bagi kehidupan organisasi, manusialah yang mengatur dan menjalankan sarana dan prasarana yang ada dalam organisasi. Dengan demikian pengelolaan praktik-praktik SDM berperan kritikal meningkatkan kinerja organisasional (Tjahjono, 2005; Palupi, 2017). Oleh karena itu, dalam upaya mendukung pencapaian tujuan organisasi tersebut, diperlukan sumber daya manusia yang berkualitas dan profesional. Keberhasilan suatu organisasi sangat erat kaitannya dengan kualitas kinerja para anggotanya, sehingga organisasi dituntut untuk selalu mengembangkan dan meningkatan kinerja dari para anggotanya. 
Peningkatan kinerja para anggota juga erat kaitannya dengan bagaimana organisasi meningkatkan kemampuan setiap anggota organisasi melalui pelatihan. Abozed, Melaine, dan Saci (2009) menyatakan program pelatihan untuk meningkatkan keterampilan karyawan merupakan tujuan utama organisasi dalam rangka mencapai tujuan perusahaan. Program pelatihan yang efektif harus memiliki dukungan yang kuat dari pimpinan dan mampu melayani sebagai peran positif untuk bawahan (Kumara dan Utama, 2016). Tidak hanya faktor pelatihan yang harus dikembangkan perusahaan untuk meningkatkan kinerja karyawan. Setiap organisasi harus memiliki ciri khas yang membedakannya dengan organisasi lain dan menjadikannya sebagai identitas bagi organisasi.

Budaya dapat menjadi kekuatan yang positif atau negatif, dalam hubungannya dengan efektivitas pencapaian prestasi perusahaan /organisasi bersangkutan. Kinerja yang tinggi merupakan hasil dari konsistensi budaya (Zahriyah et.al 2015). Budaya yang kuat ditandai oleh nilai-nilai inti yang dipegang teguh dan disepakati secara luas dalam sebuah organisasi, semakin banyak anggota yang menerima nilai-nilai tersebut semakin kuat budayanya (Robbins dan Judge, 2014). Keberhasilan suatu organisasi sangat erat kaitannya dengan kualitas kinerja para anggotanya, sehingga organisasi dituntut untuk selalu mengembangkan SDM dan meningkatkan kinerja dari para anggotanya melalui penciptaan kepuasan kerja karyawan mereka.

Salah satu masalah dalam mengelola SDM adalah masalah kepuasan kerja. Robbins dan Judge (2014) menyatakan bahwa karyawan yang puas akan mampu meningkatkan kepuasan dan kesetiaan pelanggan. Karyawan yang puas memiliki kemungkinan kecil untuk mengundurkan diri, sehingga pelanggan lebih sering menjumpai wajah-wajah akrab dan menerima layanan yang berpengalaman. Ciri-ciri tersebut membangun kepuasan dan kesetiaan pelanggan. Adanya peningkatan kepuasan kerja pada karyawan tentu berdampak pada kinerja yang ditunjukkannya.

Penelitian ini akan meneliti tentang pengaruh pelatihan dan Budaya Organisasional terhadap kinerja karyawan dengan kepuasan kerja sebagai variabel intervening. Jenis penelitian ini adalah penelitian kuantitatif. Responden dalam penelitian ini adalah 73 karyawan pada departemen SDM di PT. MADUBARU PG/PS MADUKISMO. PT Madubaru PG/PS Madukismo adalah pabrik gula dan pabrik alkohol/spirtus di Daerah Istimewa Yogyakarta dan mengemban tugas untuk ikut mensukseskan program pengadaan pangan Nasional, khususnya gula pasir. Perusahaan ini merupakan salah satu perusahaan tertua di Yogyakarta. Berdirinya perusahaan ini di prakarsai oleh Sri Sultan Hamengkubuwono IX oleh karena itu peneliti ingin mengetahui apakah Budaya Organisasional di perusahaan ini erat dengan budaya-budaya yang diturunkan oleh sang pendiri. Dengan di kaitkan dengan variabel kepuasan kerja dan kinerja. Oleh karena itu penelitian ini sangat menarik dan layak untuk diteliti lebih lanjut.

\section{TINJAUAN PUSTAKA}

\section{Pelatihan}

Snell \& Bohlander (2013:276) menjelaskan pelatihan merupakan istilah yang sering digunakan untuk menggambarkan upaya yang diprakarsai oleh organisasi untuk mendorong pembelajaran di antara para anggotanya. Menurut Snell \& Bohlander (2013:313) pelatihan dapat digunakan untuk beberapa tujuan salah satunya ialah menjadikan karyawan lebih cepat dalam peningkatan pengetahuan, skill dan attitude sehingga menjadikan kemungkinan dalam meraih sukses lebih tinggi. Dalam segi lain, pelatihan dilakukan untuk memberikan kepercayaan kepada karyawan bahwa mereka adalah bagian dari organisasi. Ini dilakukan untuk mencegah turn-over karyawan maupun untuk mencegah karyawan keluar dari organisasi. Hal ini sejalan dengan tujuan organisasi tempat penelitian dimana organisasi ini mengharapkan dengan diberikannya pelatihan, karyawan akan memiliki kinerja yang lebih baik. Dimensi dan indikator pelatihan :

\section{a. Assessment}

b. Desain 


\section{c. Implementasi \\ d. Evaluasi}

\section{Budaya Organisasional}

Robbin (2002:279) Budaya Organisasional adalah suatu sistem pengertian bersama yang dipegang oleh anggota-anggota suatu organisasi, yang membedakan organisasi tersebut dari organisasi lainnya. Lebih lanjut Robbin menyebutkan ada 7 elemen penting suatu budaya, yaitu: inovasi dan pengambilan resiko, perhatian terhadap detail, orientasi terhadap hasil, orientasi terhadap individu, orientasi terhadap tim, agresivitas, dan stabilitas. Budaya organisasional menjadi identitas dan kepribadian organisasi bahkan berperan strategis dalam menentukan keefektifan di dalam organisasi (Tjahjono, 2004).

Sedangkan Gibson, dkk (2000: 30) mendefinisikan bahwa Budaya Organisasional adalah apa yang karyawan rasakan dan bagaimana persepsi ini menciptakan pola keyakinan, nilai-nilai, dan harapan. Menurut Jones (2004: 195), budaya organisasional adalah seperangkat nilai-nilai bersama dan norma-norma yang mengendalikan interaksi anggota organisasi dengan satu sama lain dan dengan orang-orang di luar organisasi. Dimensi dalam Budaya Organisasional adalah :
a. Inovasi dan pengambilan resiko
b. Perhatian terhadap detail
c. Orientasi terhadap hasil
d. Orientasi terhadap individu
e. Orientasi terhadap tim
f. Agresivitas
g. Stabilitas

\section{Kepuasan Kerja}

Menurut Robbins (2014), kepuasan kerja adalah sikap umum terhadap pekerjaan seseorang, selisih antara banyaknya ganjaran yang diterima seorang pekerja dengan banyaknya yang mereka yakini seharusnya mereka terima. Kepuasan kerja merupakan bentuk perasaan seseorang terhadap pekerjaannya, situasi kerja dan hubungan dengan rekan kerja (Pangesti et al., 2013). Dengan demikian kepuasan kerja merupakan sesuatu yang penting untuk dimiliki oleh seorang karyawan, dimana mereka dapat berinteraksi dengan lingkungan kerjanya sehingga pekerjaan dapat dilaksanakan dengan baik dan sesuai dengan tujuan perusahaan. Menurut Robbins (2014) indikator dalam kepuasan kerja yaitu:

a. Pekerjaan yang secara mental menantang

b. Penghargaan yang sesuai

c. Kondisi kerja yang mendukung

d. Rekan kerja yang mendukung

\section{Kinerja}

Gibson et al. (2012) kinerja adalah hasil karya timbul dari suatu kombinasi usaha, kemampuan/keterampilan dan pengalaman seseorang. Dari pemahaman/mengenai prestasi kerja tersebut dapatlah disimpulkan bahwa kemampuan (usaha), motivasi, pengalaman dan kesempatan merupakan faktor-faktor yang menentukan tingkat prestasi kerja seseorang. Seorang karyawan akan memiliki prestasi kerja yang baik jika didukung oleh kekuatan faktor-faktor tersebut. Menurut Mathis dan Jackson (2006:378), kinerja para karyawan individual adalah faktor yang mempengaruhi keberhasilan suatu organisasi. Selain karyawan dapat menjadi keunggulan bersaing, 
mereka juga dapat menjadi liabilitas atau penghambat. Ketika karyawan terus menerus meninggalkan perusahaan dan ketika karyawan bekerja namun tidak efektif, maka sumber daya manusia dalam organisasi dalam keadaan rugi. Menurut Mathis dan Jackson (2006:378) dimensi dalam kinerja yaitu:
a. Kuantitas
b. Kualitas
c. Ketepatan
d. Kehadiran
e. Kemampuan bekerjasama

\section{Penelitian Terdahulu}

Anitha dan Kumar (2016) meneliti tentang "A Study On The Impact Of Training On Employee Performance In Private Insurance Sector, Coimbatore District. Variabel Independen yang digunakan adalah Pelatihan sedangkan variabel Dependen adalah Kinerja karyawan. Sampel dalam penelitian ini adalah Karyawan perusahaan asuransi di India. Alat analisis menggunakan ttest dan Chi Square. Hasil penelitian ini adalah Terdapat perbedaan kinerja karyawan sebelum dan sesudah pelatihan.

Penelitian Ubeda-garc1, et.al (2010) mengenai "Does training influence organisational performance? Analysis of the Spanish hotel sector". Variabel Independen yang digunakan adalah Pelatihan sedangkan variabel Dependen adalah Kinerja karyawan. Sampel dalam penelitian ini adalah 112 CEO Hotel di Spanyol. Alat analisis regresi berganda. Hasil penelitian ini adalah Pelatihan berpengaruh signifikan terhadap kinerja organisasi seperti kinerja karyawan, kepuasan pelanggan, kinerja keuangan, produktivitas

Penelitian Gunaraja (2014) meneliti mengenai "Organizational Corporate Culture on Employee Performance. Variabel Independen yang digunakan adalah Budaya Organisasional sedangkan variabel Dependen adalah Kinerja karyawan. Sampel dalam penelitian ini adalah 88 karyawan bank di Chenai India. Alat analisis regresi berganda. Hasil penelitian ini adalah Budaya Organisasional berpengaruh signifikan terhadap kinerja karyawan.

Penelitian Paschal \& Nizam (2016) meneliti mengenai "Effects of Organisational Culture on Employees Performance: Case of Singapore Telecommunication". Variabel Independen yang digunakan adalah Budaya Organisasional sedangkan variabel Dependen adalah Kinerja karyawan. Sampel dalam penelitian ini adalah 150 karyawan di perusahaan telekomunikasi Singapura. Alat analisis regresi berganda. Hasil penelitian ini adalah Budaya Organisasional berpengaruh signifikan terhadap kinerja karyawan.

Penelitian Latif (2012) meneliti mengenai "An integrated model of training effectiveness and satisfaction with employee development interventions". Variabel Independen yang digunakan adalah Pelatihan sedangkan variabel Dependen adalah kepuasan kerja. Sampel dalam penelitian ini adalah 127 responden di Pakistan. Alat analisis regresi berganda. Hasil penelitian ini adalah Pelatihan yang terdiri dari pelatih, teknik pelatihan, manajemen waktu, konten pelatihan, fasilitas pelattihan, objektifitas pelatihan, dan umpan balik pelatihan. Sampel dalam penelitian ini adalah 363 karyawan di pakistan. Alat analisis korelasi. Hasil penelitian ini adalah Pelatihan berhubungan signifikan terhadap kepuasan kerja.

Belias dan Koustelios (2014) meneliti mengenai "Organizational Culture and Job Satisfaction: A Review". Variabel Independen yang digunakan adalah Budaya Organisasional sedangkan variabel Dependen adalah kepuasan kerja. Sampel dalam penelitian ini adalah 100 
karyawan di Yunani. Alat analisis menggunakan analisis kualitatif. Hasil penelitian ini adalah Budaya Organisasional berpengaruh terhadap kepuasan kerja.

Barakat et.al (2015) meneliti mengenai "An analysis of the impact of cultural intelligence on job satisfaction and performance". Variabel Independen yang digunakan adalah kecerdasan budaya sedangkan variabel Dependen adalah kinerja sedangkan variabel intervening adalah kepuasan kerja. Sampel dalam penelitian ini adalah 332 manajer di Brazil. Alat analisis menggunakan analisis jalur. Hasil penelitian ini adalah kecerdasan budaya berpengaruh signifikan terhadap kepuasan kerja, kecerdasan budaya berpengaruh signifikan terhadap kinerja, Kepuasan kerja memediasi pengaruh pelatihan terhadap kinerja.

Awadh dan Saad (2013) meneliti mengenai "Impact of Organizational Culture on Employee Performance". Variabel Independen yang digunakan adalah Budaya Organisasional dan variabel dependen adalah kinerja. Sampel dalam penelitian ini adalah 200 perusahaana di Malaysia. Alat analisis menggunakan analisis regresi. Hasil penelitian ini adalah Budaya Organisasional berpengaruh signifikan terhadap kinerja karyawan.

\section{Hipotesis Penelitian}

Berdasarkan dari latar belakang, tujuan penelitian, rumusan masalah, dan landasan teori maka hipotesis yang diajukan dalam penelitian adalah sebagai berikut:

$\mathrm{H}_{1}$ : Pelatihan berpengaruh terhadap Kinerja karyawan

$\mathrm{H}_{2}$ : Budaya Organisasional berpengaruh terhadap Kinerja karyawan

$\mathrm{H}_{3}$ : Pelatihan berpengaruh terhadap Kepuasan Kerja

$\mathrm{H}_{4}$ : Budaya Organisasional berpengaruh terhadap Kepuasan Kerja

$\mathrm{H}_{5}$ : Kepuasan Kerja berpengaruh terhadap Kinerja karyawan

$\mathrm{H}_{6}$ : Kepuasan kerja memediasi pengaruh Pelatihan Terhadap Kinerja karyawan

$\mathrm{H}_{7}$ : Kepuasan kerja memediasi pengaruh Budaya Organisasional Terhadap Kinerja karyawan

\section{METODE PENELITIAN}

\section{Populasi dan Sampel}

Populasi dalam penelitian ini adalah seluruh karyawan departemen SDM di PT. MADUBARU PG/PS MADUKISMO yang berjumlah 73 orang. Sampel dalam penelitian ini diambil dengan menggunakan metode sensus. Metode sensus yaitu cara pengumpulan data apabila seluruh elemen populasi diselidiki satu persatu. Data yang diperoleh tersebut merupakan hasil pengolahan sensus disebut sebagai data yang sebenarnya (true value), atau sering juga disebut parameter. Alasan peneliti menggunakan metode sensus adalah karena jumlah populasi yang relatif kecil. Maka dari itu peneliti mengambil semua populasi untuk dijadikan sebagai sampel.

\section{Variabel Penelitian dan Pengukuran}

\section{a. Variabel Dependen}

Variabel terikat merupakan variabel yang dipengaruhi atau yang menjadi akibat, karena adanya variabel bebas. Variabel dependen dalam penelitian ini adalah variabel kinerja.

b. Variabel Independen 
Variabel independen merupakan variabel yang mempengaruhi atau yang menjadi sebab perubahannya atau timbulnya variabel dependen (terikat). Variabel independen dalam penelitian ini adalah variabel pelatihan dan Budaya Organisasional

c. Variabel Intervening

Variabel ini merupakan variabel penyela/antara yang terletak di antara variabel independen dan dependen, sehingga variabel independen tidak langsung mempengaruhi berubahnya atau timbulnya variabel dependen. Variabel intervening dalam penelitian ini adalah variabel kepuasan kerja.

\section{Metode Analisis Data}

Dalam penelitian ini, analisis data menggunakan Structural Equation Model (SEM), dengan menggunakan bantuan software PLS (Partial Least Square). Menurut Wiyono (2011), PLS adalah salah satu teknik SEM yang mampu menganalisis variabel laten, variabel indikator dan kesalahan pengukuran secara langsung. PLS merupakan metode analisis yang powerfull karena dapat diterapkan pada semua skala data, tidak banyak membutuhkan asumsi, dan ukuran sampel tidak harus besar. Software yang digunakan adalah SmartPLS 2.0

Metode pengumpulan data yang digunakan dalam penelitian ini adalah:

\section{a. Tinjauan Kepustakaan}

Tinjauan kepustakaan yaitu penelitian ini dilakukan dengan cara mengumpulkan, membaca dan mempelajari literatur, jurnal dan buku-buku serta refrensi yang relevan dengan permasalahan yang dikaji untuk mendapatkan kejelasan konsep teori dalam upaya penyusunan landasan teori yang sangat berguna dalam pembahasan.

b. Tinjauan Lapangan

Tinjauan lapangan yaitu penelitian yang dilakukan dengan mendapatkan data langsung melalui kuesioner. Kuesioner adalah cara pengumpulan data dengan menggunakan daftar pertanyaan yang diberikan pada responden. Beberapa kelebihan dari kuesinoner adalah lebih efisien menggunakan waktu dalam pengumpulan data, data yang diperoleh asli dan dapat diterapkan untuk pengumpulan data dalam lingkungan yang cukup luas. Kekurangan dari kuesioner adalah terkadang responden tidak menjawab pertanyaan dan mengisinya sesuai dengan kondisi, responden terbatasi oleh pilihan jawaban- jawaban tertentu dan lain-lain.

Dalam penelitian ini skala yang digunakan adalah skala Likert. Menurut Ghozali (2013:47) skala Likert digunakan untuk mengukur sikap, pendapat, dan persepsi seseorang atau sekolompok orang tentang fenomena sosial yang berisi 5 tingkatan prefensi jawaban dengan pilihan sebagai berikut:

$1=$ Sangat Tidak Setuju (STS)

2 = Tidak Setuju (TS)

$3=$ Ragu-ragu $(\mathrm{R})$

$4=$ Setuju $(\mathrm{S})$

5 = Sangat Setuju (SS) 


\section{Kerangka Pemikiran}

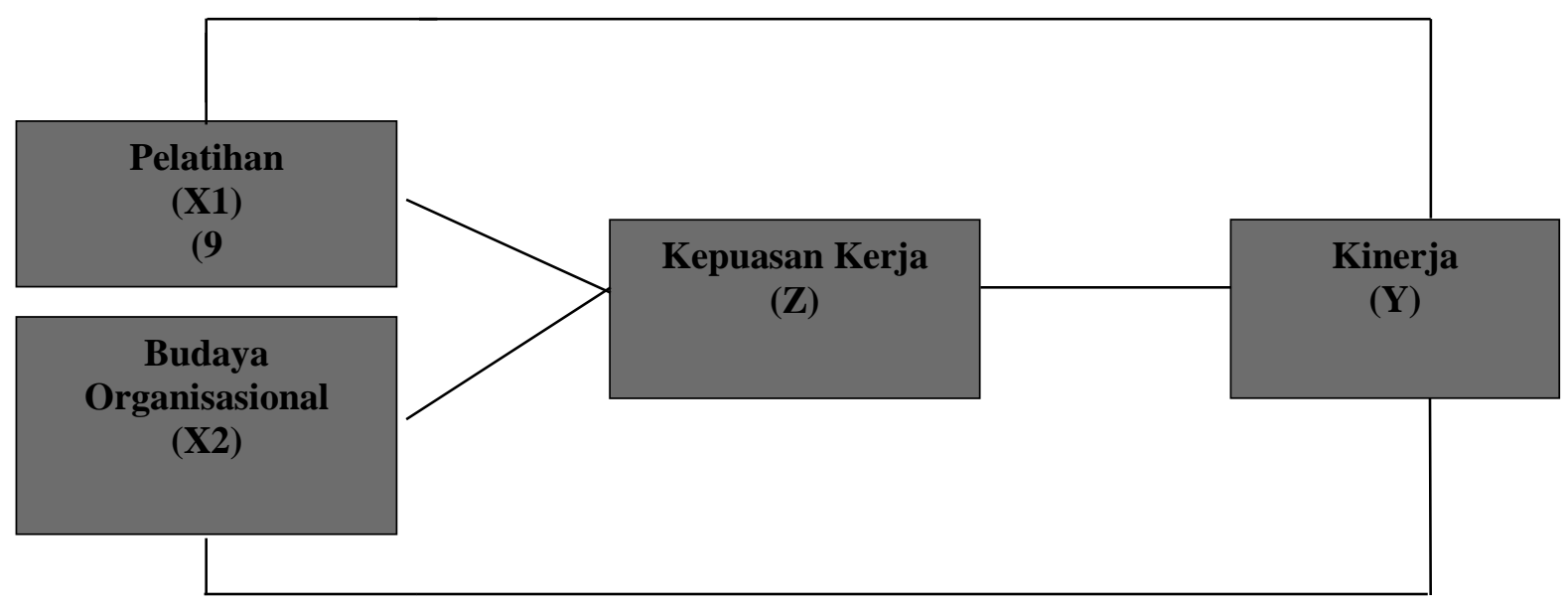

Gambar 1. Kerangka Pemikiran

\section{HASIL PENELITIAN DAN PEMBAHASAN}

\section{Pengukuran Model}

Pada pengukuran model ini menunjukkan indikator-indikator yang dipergunakan dalam penelitian valid dan reliabel atau tidak, hasil pengujian pada path diagram model penelitian selengkapnya adalah sebagai berikut:

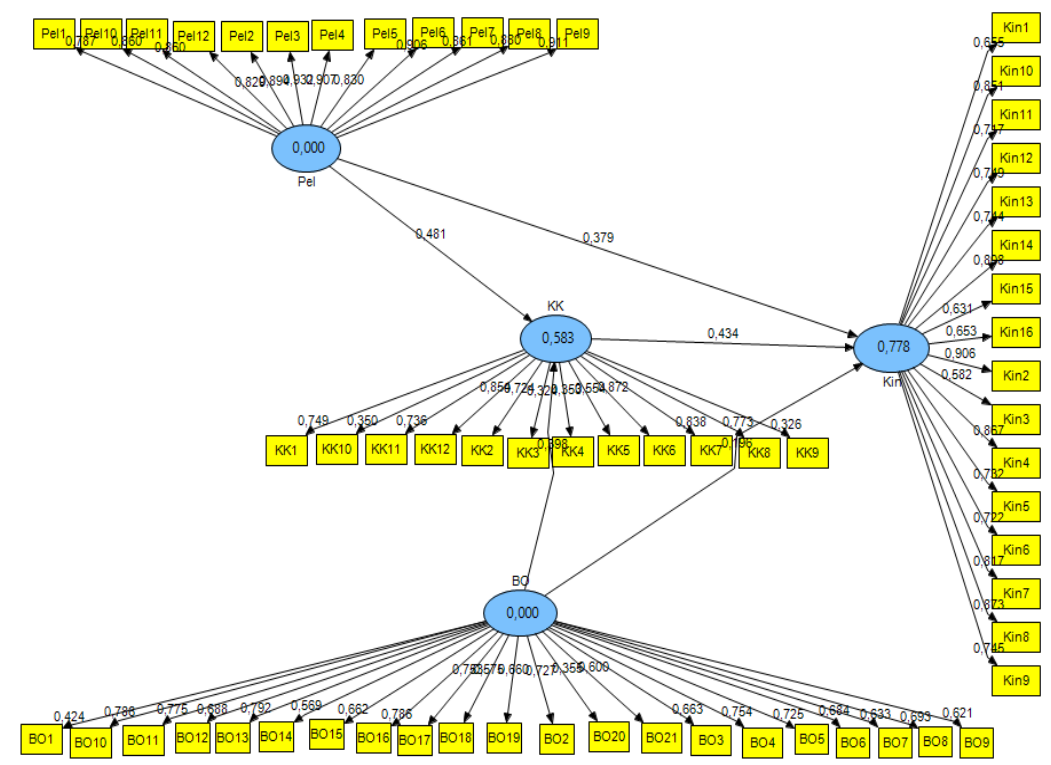

Gambar 2. Model Awal Path Diagram

Pada gambar 2, konstruk pelatihan dibentuk atau diukur dengan 12 indikator yaitu Pel1 sampai dengan Pel12, selanjutnya konstruk Budaya Organisasional dibentuk dengan 21 indikator yaitu BO1 sampai dengan BO21, konstruk kepuasan kerja dibentuk dengan 12 indikator yaitu KK1 sampai dengan KK12, dan selanjutnya konstruk kinerja karyawan dibentuk dengan 16 indikator yaitu Kin1 sampai dengan Kin16. 


\section{Uji Validitas dan Reliabilitas Variabel Laten}

Pada pengujian ini digunakan untuk menilai outer model yang meliputi convergent validity diukur dari nilai outer loading, discriminant validity diukur dengan nilai AVE, dan composite reliability atau CR untuk mengukur tingkat reliabilitas.

\section{Convergent Validity}

Convergent validity dari measurement model dengan indikator refleksif dapat dilihat dari korelasi antara skor item/ indikator dengan skor konstruknya. Indikator individu dianggap valid jika memiliki nilai korelasi di atas 0,50 . Hasil loading item pada outer model dapat dilihat dalam tabel berikut:

Tabel 1. Hasil Uji Convergent Validity - Outer Loading

\begin{tabular}{|c|c|c|c|c|}
\hline Variabel & Item & Nilai Loading & Kriteria & Keterangan \\
\hline \multirow[t]{12}{*}{ Pelatihan } & PEL1 & 0,786654 & 0,5 & Valid \\
\hline & PEL2 & 0,894177 & 0,5 & Valid \\
\hline & PEL3 & 0,932120 & 0,5 & Valid \\
\hline & PEL4 & 0,907123 & 0,5 & Valid \\
\hline & PEL5 & 0,830474 & 0,5 & Valid \\
\hline & PEL6 & 0,906459 & 0,5 & Valid \\
\hline & PEL7 & 0,860558 & 0,5 & Valid \\
\hline & PEL8 & 0,880310 & 0,5 & Valid \\
\hline & PEL9 & 0,911407 & 0,5 & Valid \\
\hline & PEL10 & 0,860440 & 0,5 & Valid \\
\hline & PEL11 & 0,860075 & 0,5 & Valid \\
\hline & PEL12 & 0,829214 & 0,5 & Valid \\
\hline \multirow[t]{10}{*}{ Budaya Organisasional } & BO1 & 0,424480 & 0,5 & Tidak Valid \\
\hline & $\mathrm{BO} 2$ & 0,726811 & 0,5 & Valid \\
\hline & BO3 & 0,662661 & 0,5 & Valid \\
\hline & BO4 & 0,753676 & 0,5 & Valid \\
\hline & BO5 & 0,725307 & 0,5 & Valid \\
\hline & BO6 & 0,684298 & 0,5 & Valid \\
\hline & BO7 & 0,633376 & 0,5 & Valid \\
\hline & BO8 & 0,692838 & 0,5 & Valid \\
\hline & BO9 & 0,620671 & 0,5 & Valid \\
\hline & BO10 & 0,786491 & 0,5 & Valid \\
\hline
\end{tabular}




\begin{tabular}{|c|c|c|c|c|}
\hline & BO11 & 0,775251 & 0,5 & Valid \\
\hline & BO12 & 0,688308 & 0,5 & Valid \\
\hline & BO13 & 0,791792 & 0,5 & Valid \\
\hline & BO14 & 0,568819 & 0,5 & Valid \\
\hline & BO15 & 0,662325 & 0,5 & Valid \\
\hline & BO16 & 0,786491 & 0,5 & Valid \\
\hline & BO17 & 0,753383 & 0,5 & Valid \\
\hline & BO18 & 0,574788 & 0,5 & Valid \\
\hline & BO19 & 0,660425 & 0,5 & Valid \\
\hline & $\mathrm{BO} 20$ & 0,354848 & 0,5 & Tidak Valid \\
\hline & $\mathrm{BO} 21$ & 0,600481 & 0,5 & Valid \\
\hline Kepuasan kerja & KK1 & 0,748624 & 0,5 & Valid \\
\hline & KK2 & 0,724474 & 0,5 & Valid \\
\hline & KK3 & 0,323537 & 0,5 & Valid \\
\hline & KK4 & 0,352763 & 0,5 & Tidak Valid \\
\hline & KK5 & 0,554182 & 0,5 & Valid \\
\hline & KK6 & 0,871966 & 0,5 & Valid \\
\hline & KK7 & 0,838444 & 0,5 & Valid \\
\hline & KK8 & 0,773453 & 0,5 & Valid \\
\hline & KK9 & 0,326098 & 0,5 & Tidak Valid \\
\hline & KK10 & 0,350287 & 0,5 & Tidak Valid \\
\hline & KK11 & 0,735515 & 0,5 & Valid \\
\hline & KK12 & 0,854458 & 0,5 & Valid \\
\hline Kinerja karyawan & Kin1 & 0,655422 & 0,5 & Valid \\
\hline & Kin2 & 0,905660 & 0,5 & Valid \\
\hline & Kin3 & 0,581586 & 0,5 & Valid \\
\hline & Kin4 & 0,867259 & 0,5 & Valid \\
\hline & Kin5 & 0,732189 & 0,5 & Valid \\
\hline
\end{tabular}




\begin{tabular}{|c|c|c|c|c|}
\hline & Kin6 & 0,721851 & 0,5 & Valid \\
\cline { 2 - 5 } & Kin7 & 0,816572 & 0,5 & Valid \\
\cline { 2 - 5 } & Kin8 & 0,873144 & 0,5 & Valid \\
\cline { 2 - 5 } & Kin9 & 0,744725 & 0,5 & Valid \\
\cline { 2 - 6 } & Kin10 & 0,850602 & 0,5 & Valid \\
\cline { 2 - 6 } & Kin11 & 0,716851 & 0,5 & Valid \\
\cline { 2 - 6 } & Kin12 & 0,748722 & 0,5 & Valid \\
\cline { 2 - 6 } & Kin13 & 0,744328 & 0,5 & Valid \\
\cline { 2 - 6 } & Kin14 & 0,808209 & 0,5 & Valid \\
\cline { 2 - 5 } & Kin15 & 0,631370 & 0,5 & Valid \\
\hline & Kin16 & 0,653045 & 0,5 & Valid \\
\hline
\end{tabular}

Berdasarkan nilai loading diatas, maka masih terdapat beberapa konstruk atau item dari variabel penelitian yang belum memenuhi convergent validity atau dinyatakan tidak valid dikarenakan item tersebut memiliki nilai loading di bawah 0,5. Dengan demikian dilakukan pengujian lanjutan sampai diperoleh semua item pada variabel penelitian dinyatakan valid dengan cara tidak mengikutkan item-item yang tidak valid tersebut pada pengujian selanjutnya. Sesuai dengan pengujian selanjutnya maka diperoleh hasil pengujian path diagram yang sudah memenuhi convergent validity atau dinyatakan valid yaitu sebagai berikut:

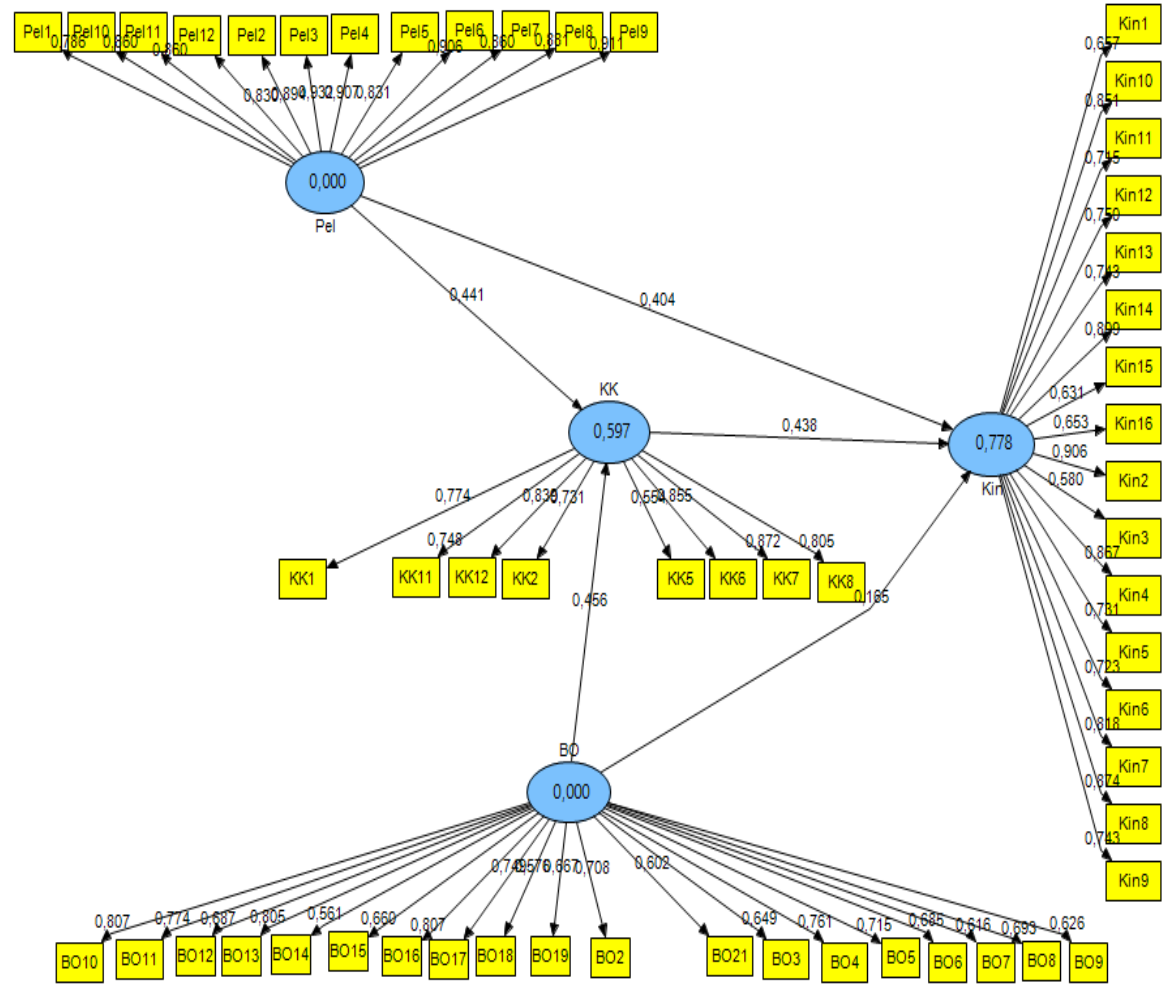

Gambar 3. Model Path Diagram yang Memenuhi Convergent Validity 
Hasil loading item pada outer model dapat dilihat dalam tabel berikut:

Tabel 2. Hasil Uji Convergent Validity - Outer Loading

\begin{tabular}{|c|c|c|c|c|}
\hline Variabel & Item & Nilai Loading & Kriteria & Keterangan \\
\hline \multirow[t]{12}{*}{ Pelatihan } & PEL1 & 0,786435 & 0,5 & Valid \\
\hline & PEL2 & 0,894269 & 0,5 & Valid \\
\hline & PEL3 & 0,932113 & 0,5 & Valid \\
\hline & PEL4 & 0,907010 & 0,5 & Valid \\
\hline & PEL5 & 0,830750 & 0,5 & Valid \\
\hline & PEL6 & 0,906315 & 0,5 & Valid \\
\hline & PEL7 & 0,860230 & 0,5 & Valid \\
\hline & PEL8 & 0,880611 & 0,5 & Valid \\
\hline & PEL9 & 0,911484 & 0,5 & Valid \\
\hline & PEL10 & 0,860447 & 0,5 & Valid \\
\hline & PEL11 & 0,859750 & 0,5 & Valid \\
\hline & PEL12 & 0,829554 & 0,5 & Valid \\
\hline \multirow[t]{15}{*}{ Budaya Organisasional } & $\mathrm{BO} 2$ & 0,708005 & 0,5 & Valid \\
\hline & $\mathrm{BO} 3$ & 0,648750 & 0,5 & Valid \\
\hline & $\mathrm{BO} 4$ & 0,761442 & 0,5 & Valid \\
\hline & BO5 & 0,714554 & 0,5 & Valid \\
\hline & BO6 & 0,684565 & 0,5 & Valid \\
\hline & BO7 & 0,616339 & 0,5 & Valid \\
\hline & BO8 & 0,692521 & 0,5 & Valid \\
\hline & BO9 & 0,625512 & 0,5 & Valid \\
\hline & BO10 & 0,807485 & 0,5 & Valid \\
\hline & BO11 & 0,774496 & 0,5 & Valid \\
\hline & BO12 & 0,686863 & 0,5 & Valid \\
\hline & BO13 & 0,804632 & 0,5 & Valid \\
\hline & BO14 & 0,561249 & 0,5 & Valid \\
\hline & BO15 & 0,660128 & 0,5 & Valid \\
\hline & BO16 & 0,807485 & 0,5 & Valid \\
\hline
\end{tabular}




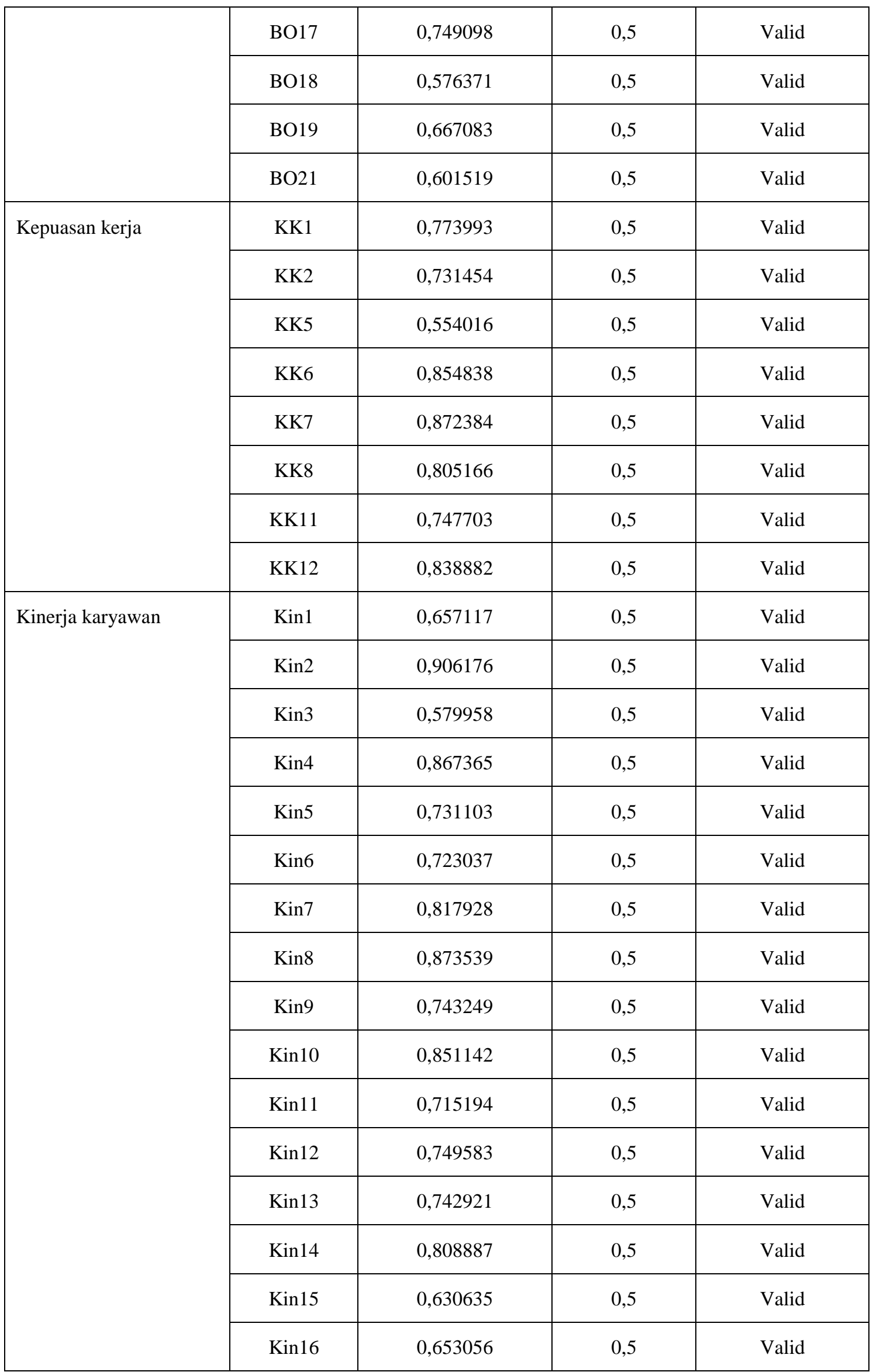


Berdasarkan nilai loading diatas, maka dapat disimpulkan bahwa pada tahap pengujian ini semua item dari variabel penelitian sudah valid dan telah memenuhi convergent validity atau dinyatakan valid dikarenakan seluruh item memiliki nilai loading di atas 0,5. Dari pengujian ini dapat disimpulkan bahwa pada tahap pengujian ini semua item dari variabel penelitian valid.

\section{Discriminat Validity}

Discriminant validity dilakukan untuk memastikan bahwa setiap konsep dari masing variabel laten berbeda dengan variabel lainnya. Model mempunyai discriminant validity yang baik jika nilai avarge variance extracted (AVE) dengan nilai $(\geq 0,5)$. Hasil pengujian discriminant validity dengannilai AVE berikut ini:

Tabel 3. Hasil Uji Discriminant Validity - Nilai AVE

\begin{tabular}{|l|c|c|c|}
\hline \multicolumn{1}{|c|}{ Variabel } & AVE & Kriteria & Keterangan \\
\hline Pelatihan & 0,761268 & 0,5 & Valid \\
\hline Budaya Organisasional & 0,5184524 & 0,5 & Valid \\
\hline Kepuasan kerja & 0,605488 & 0,5 & Valid \\
\hline Kinerja karyawan & 0,575728 & 0,5 & Valid \\
\hline
\end{tabular}

Berdasarkan hasil diatas dapat dijelaskan bahwa dari hasil keempat variabel memiliki nilai AVE diatas 0,5 sehingga dapat dikatakan data memiliki discriminant validity yang baik.

3. Uji reliabilitas dengan composite reliability

Kriteria reliabilitas dapat dilihat dari nilai composite reliability dari masing-masing variabel. Nilai batas untuk tingkat reliabilitas diatas 0,7 . Berikut hasil uji reliabilitas sebagai berikut:

Tabel 4. Hasil Uji Reliabilitas - Composite Reliability

\begin{tabular}{|l|c|c|c|}
\hline \multicolumn{1}{|c|}{ Variabel } & $\begin{array}{c}\text { Composite } \\
\text { Reliability }\end{array}$ & Kriteria & Keterangan \\
\hline Pelatihan & 0,974480 & 0,7 & Reliabel \\
\hline Budaya Organisasional & 0,946383 & 0,7 & Reliabel \\
\hline Kepuasan kerja & 0,923635 & 0,7 & Reliabel \\
\hline Kinerja karyawan & 0,955343 & 0,7 & Reliabel \\
\hline
\end{tabular}

Hasil analisis uji reliabilitas menginformasikan bahwa seluruh variabel memenuhi Cronbach's Alpha diatas 0,7 sudah memenuhi kriteria reliabel dan layak untuk digunakan dalam penelitian selanjutnya.

Berdasarkan hasil evaluasi secara keseluruhan, baik convergent validity, discriminant validity, dan uji reliabilitas dengan composite reliability yang telah dipaparkan di atas, dapat disimpulkan bahwa item pernyataan sebagai pengukur variabel merupakan pengukur yang valid dan reliabel. 


\section{Nilai R-Square}

Analisis ini menunjukkan besarnya pengaruh dari variabel eksogen kepada variabel endogennya. Berikut besarnya nilai R-Square pada hubungan antara konstruk penelitian ditunjukkan dalam tabel berikut.

Tabel 5. Nilai R-Square

\begin{tabular}{|l|c|}
\hline \multicolumn{1}{|c|}{ Konstruk } & R Square \\
\hline Kepuasan kerja & 0,597311 \\
\hline Kinerja karyawan & 0,777972 \\
\hline
\end{tabular}

Sumber: Hasil olah data primer, 2018.

Berdasarkan Tabel 5 dapat dijelaskan pengaruh dari variabel eksogen terhadap variabel endogen, diperoleh nilai R Square pada konstruk kepuasan kerja sebesar 0,597311 yang berarti pelatihan dan Budaya Organisasional mampu menjelaskan pengaruhnya pada kepuasan kerja sebesar 59,73\%. Selanjutnya diperoleh nilai R Square pada konstruk Kinerja karyawan sebesar 0,777972 yang berarti pelatihan, Budaya Organisasional dan kepuasan kerja mampu menjelaskan pengaruhnya pada kinerja sebesar 77,79\%.

\section{Pengujian Model Struktural (Inner Model)}

Pengujian ini untuk melihat ada tidaknya pengaruh dari variabel eksogen terhdap variabel endogen. Hasil analisis model struktural dapat dilihat pada model di gambar 4.3.

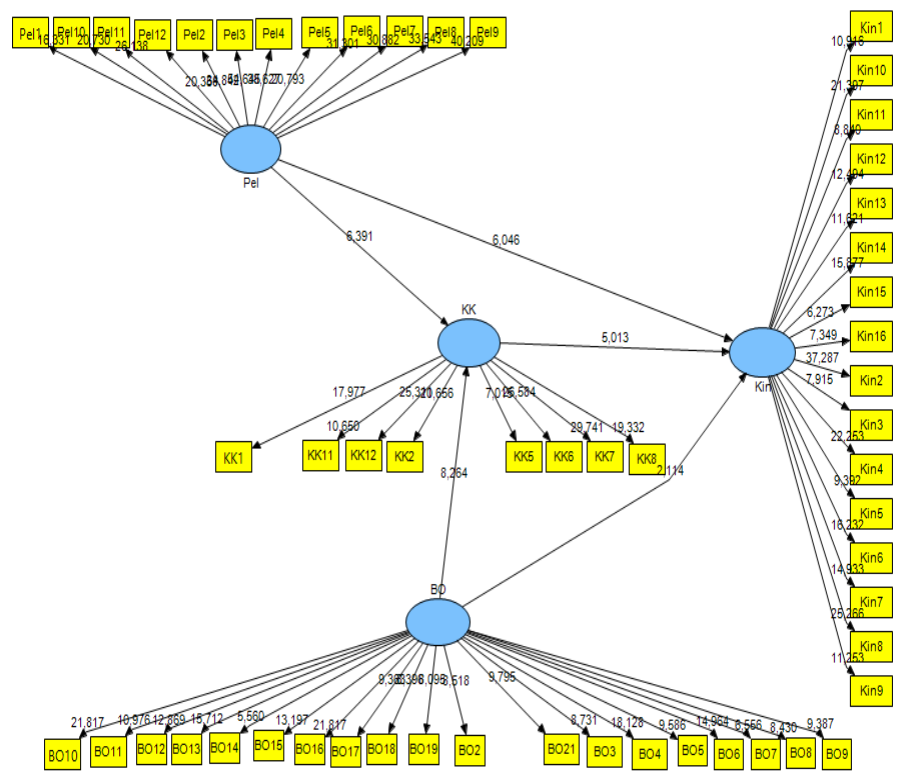

Gambar 4. Output Bootstrapping

Berdasarkan gambar di atas dapat dijelaskan hasil pengujian model struktural hubungan antar variabel penelitian seperti dalam tabel 6 . 
Tabel 6. Hasil Pengujian Model Struktural

\begin{tabular}{|l|c|c|c|}
\hline \multicolumn{1}{|c|}{ Hubungan Variabel Penelitian } & $\begin{array}{c}\text { Original Sample } \\
(\mathrm{O})\end{array}$ & $\begin{array}{c}\text { T Statistics } \\
(\mid \mathrm{O} / \text { STERR })\end{array}$ & Keterangan \\
\hline Pelatihan -> Kinerja & 0,596897 & 9,195316 & Signifikan \\
\hline $\begin{array}{l}\text { Budaya Organisasional -> } \\
\text { Kinerja }\end{array}$ & 0,365034 & 5,021730 & Signifikan \\
\hline $\begin{array}{l}\text { Pelatihan -> Kepuasan kerja } \\
\text { Budaya Organisasional-> } \\
\text { Kepuasan kerja }\end{array}$ & 0,440578 & 6,391373 & Signifikan \\
\hline Kepuasan kerja -> Kinerja & 0,437812 & 8,263971 & Signifikan \\
\hline
\end{tabular}

Sumber: Hasil olah data primer, 2018.

\section{Pengujian Hipotesis}

\section{Hipotesis pertama}

Berdasarkan Tabel 6 tentang pengaruh pelatihan (X1) terhadap kinerja karyawan (Y), koefisien regresi pelatihan diperoleh sebesar 0,596897 (positif) yang berarti apabila variabel pelatihan meningkat maka kinerja karyawan akan meningkat dan sebaliknya, dengan asumsi variabel Budaya Organisasional dan kepuasan kerja dalam keadaan konstan. Hasil perhitungan uji signifikansi dengan $\mathrm{t}$ statistik diperoleh nilai $\mathrm{t}_{\text {hitung }}$ sebesar sebesar 9,195316. Dikarenakan nilai $t_{\text {hitung }}>$ dari nilai $t_{\text {tabel }}$ atau $(9,195316>1,6694)$, maka hipotesis pertama diterima. Dengan demikian hipotesis pertama yang menyatakan pelatihan berpengaruh positif terhadap kinerja karyawan terbukti.

\section{Hipotesis kedua}

Berdasarkan Tabel 6 tentang pengaruh Budaya Organisasional (X2) terhadap kinerja karyawan (Y), koefisien regresi Budaya Organisasional diperoleh sebesar 0,365034 (positif) yang berarti apabila variabel Budaya Organisasional meningkat maka kinerja karyawan akan meningkat dan sebaliknya, dengan asumsi variabel pelatihan dan kepuasan kerja dalam keadaan konstan. Hasil perhitungan uji signifikansi dengan t statistik diperoleh nilai thitung sebesar 5,021730, Dikarenakan nilai $t_{\text {hitung }}>$ dari nilai $t_{\text {tabel }}$ atau $(5,021730>1,6694)$, maka hipotesis kedua diterima. Dengan demikian hipotesis kedua yang menyatakan Budaya Organisasional berpengaruh positif terhadap kinerja karyawan terbukti.

\section{Hipotesis ketiga}

Berdasarkan Tabel 6 tentang pengaruh pelatihan (X1) terhadap kepuasan kerja karyawan (Y), koefisien regresi pelatihan diperoleh sebesar 0,440578 (positif) yang berarti apabila variabel pelatihan meningkat maka kepuasan kerja karyawan akan meningkat dan sebaliknya, dengan asumsi variabel Budaya Organisasional dan kepuasan kerja dalam keadaan konstan. Hasil perhitungan uji

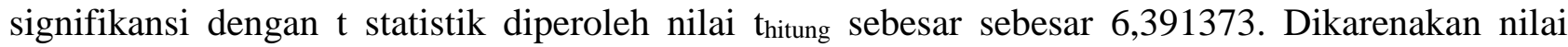
$t_{\text {hitung }}>$ dari nilai $t_{\text {tabel }}$ atau $(6,391373>1,6694)$,, maka hipotesis ketiga diterima. Dengan demikian hipotesis ketiga yang menyatakan pelatihan berpengaruh positif terhadap kepuasan kerja karyawan terbukti. 


\section{Hipotesis keempat}

Berdasarkan Tabel 6 tentang pengaruh Budaya Organisasional (X2) terhadap kepuasan kerja karyawan (Y), koefisien regresi Budaya Organisasional diperoleh sebesar 0,456360 (positif) yang berarti apabila variabel Budaya Organisasional meningkat maka kepuasan kerja karyawan akan meningkat dan sebaliknya, dengan asumsi variabel Budaya Organisasional dan kepuasan kerja dalam keadaan konstan. Hasil perhitungan uji signifikansi dengan $t$ statistik diperoleh nilai $t_{\text {hitung }}$ sebesar sebesar 8,263971. Dikarenakan nilai $t_{\text {hitung }}>$ dari nilai $t_{\text {tabel }}$ atau $(8,263971>1,6694)$, maka hipotesis keempat diterima. Dengan demikian hipotesis keempat yang menyatakan Budaya Organisasional berpengaruh positif terhadap kepuasan kerja karyawan terbukti.

\section{Hipotesis kelima}

Berdasarkan Tabel 6 tentang pengaruh kepuasan kerja (X2) terhadap kinerja karyawan (Y), koefisien regresi kepuasan kerja diperoleh sebesar 0,437812 (positif) yang berarti apabila variabel kepuasan kerja meningkat maka kinerja karyawan akan meningkat dan sebaliknya, dengan asumsi variabel kepuasan kerja dan kinerja dalam keadaan konstan. Hasil perhitungan uji signifikansi dengan $\mathrm{t}$ statistik diperoleh nilai $t_{\text {hitung }}$ sebesar sebesar 5,013038. Dikarenakan nilai $t_{\text {hitung }}>$ dari nilai $t_{\text {tabel }}$ atau $(5,013038>1,6694)$, maka hipotesis kelima diterima. Dengan demikian hipotesis kelima yang menyatakan kepuasan kerja berpengaruh positif terhadap kinerja karyawan terbukti.

\section{Hipotesis keenam}

Pada Tabel 6 dapat menjelaskan hasil pengujian hipotesis keenam yang menganalisis pengaruh kepuasan kerja dalam memediasi hubungan antara pelatihan dan kinerja karyawan, berdasarkan hasil analisis tersebut diperoleh nilai thitung pada pengaruh pelatihan terhadap kepuasan kerja sebesar 6,391373 dan kemudian diperoleh nilai thitung pada pengaruh kepuasan kerja terhadap kinerja karyawan sebesar 5,013038. Dikarenakan kedua jalur pengaruh tersebut signifikan atau memiliki nilai $t_{h i t u n g}$ lebih besar dari nilai tabel maka dapat dinyatakan adanya pengaruh tidak langsung dari pelatihan terhadap kinerja karyawan melalui kepuasan kerja. Dengan demikian, hipotesis keenam yang menyatakan kepuasan kerja memediasi pengaruh pelatihan terhadap kinerja karyawan diterima atau terbukti.

\section{Hipotesis ketujuh}

Pada Tabel 6 dapat menjelaskan hasil pengujian hipotesis ketujuh yang menganalisis pengaruh kepuasan kerja dalam memediasi hubungan antara Budaya Organisasional dan kinerja karyawan, berdasarkan hasil analisis tersebut diperoleh nilai $t_{\text {hitung }}$ pada pengaruh Budaya Organisasional terhadap kepuasan kerja sebesar 8,263971 dan kemudian diperoleh nilai thitung pada pengaruh kepuasan kerja terhadap kinerja karyawan sebesar 5,013038. Dikarenakan kedua jalur pengaruh tersebut signifikan atau memiliki nilai thitung lebih besar dari nilai tabel maka dapat dinyatakan adanya pengaruh tidak langsung dari Budaya Organisasional terhadap kinerja karyawan melalui kepuasan kerja. Dengan demikian, hipotesis ketujuh yang menyatakan kepuasan kerja memediasi pengaruh Budaya Organisasional terhadap kinerja karyawan diterima atau terbukti.

\section{KESIMPULAN DAN SARAN}

\section{Kesimpulan}

Berdasarkan hasil analisis dan pembahasan di atas, maka dapat ditarik beberapa kesimpulan dari hasil penelitian ini.

1. Pelatihan berpengaruh positif dan signifikan terhadap kinerja karyawan PT. Madubaru.

2. Budaya Organisasional berpengaruh positif dan signifikan terhadap kinerja karyawan PT. Madubaru. 
3. Pelatihan berpengaruh positif dan signifikan terhadap kepuasan kerja karyawan PT. Madubaru.

4. Budaya Organisasional berpengaruh positif dan signifikan terhadap kepuasan kerja karyawan PT. Madubaru.

5. Kepuasan kerja berpengaruh positif dan signifikan terhadap kinerja karyawan PT. Madubaru.

6. Kepuasan kerja mampu memediasi pengaruh pelatihan terhadap kinerja karyawan PT. Madubaru.

7. Kepuasan kerja mampu memediasi pengaruh Budaya Organisasional terhadap kinerja karyawan PT. Madubaru.

\section{Saran} berikut :

Berdasarkan hasil penelitian ini, penulis dapat menyampaikan beberapa saran sebagai

1. Sehubungan dengan signifikannya pengaruh dari kepuasan kerja dalam memediasi pelatihan dan Budaya Organisasional, maka yang pertama sebaiknya dilakukan perusahaan adalah membuat karyawan puas dalam menjalankan pekerjaannya. Dengan puasnya karyawan akan menyebabkan tingginya hasil kerja yang dicapai oleh karyawan.

2. Bagi peneliti lain yang ingin melakukan penelitian mengenai kinerja karyawan, model ini dapat dikembangkan dengan menambah variabel lain yang mungkin dapat mempengaruhi kepuasan kerja dan kinerja karyawan, seperti variabel kompensasi dan Budaya Organisasional.

\section{DAFTAR PUSTAKA}

Abozed, M., Melaine, Y., \& Saci, K. (2009). The Influence Of Work Environmental Factors On Motivation To Transfer Management Training : Case Study Of The Libyan Oil Industry. In In 4 the Annual Conference Liverpool BEAN (pp. 1-14).

Anitha, R., \& Kumar, A. (2016). A Study On The Impact Of Training On Employee Performance In Private Insurance Sector, Coimbatore District. International Journal of Management Research Dan Review, 6(8), 1079-1090.

Awadh, A. M., \& Saad, M. (2013). Impact of Organizational Culture on Employee Performance. International Review of Management and Business Research, 2(1), 168-176.

Barakat, L. L., Lorenz, M. P., \& Ramsey, J. R. (2015). Global managers An analysis of the impact of cultural and performance. International Journal of Emerging Markets, 10(4), 781-800.

Belias, D., \& Koustelios, A. (2014). Organizational Culture and Job Satisfaction: A Review. International Review of Management and Marketing, 4(2), 132-149.

Ghozali, I. (2013). Analisis Multivariat dengan Program SPSS. Semarang: Penerbit Universitas Diponegoro.

Gibson, J. L., Ivancevich, J. M., Donnelly, J. H., \& Konopaske, R. (2012). Organizations: Behavior, Structure, Processes (14th ed.). New York: McGraw-Hill.

Gunaraja, T. M. (2014). Organizational Corporate Culture on Employee Performance. IOSR Journal of Business and Management (IOSR-JBM), 16(11), 38-42.

Kumara, I. W. S. E., \& Utama, I. W. M. U. (2016). Dengan Mediasi Kepemimpinan Pada Hotel Satriya Cottages Kuta-Bali. E-Jurnal Manajemen Unud, 5(3), 1399-1428. 
Latif, K. F. (2012). An integrated model of training effectiveness and satisfaction with employee development interventions. Industrial And Commercial Training, 44(4), 211-222. https://doi.org/10.1108/00197851211231487

Palupi, M, (2017). Catatan studi evolusi manajemen sumberdaya manusia strategik. Jurnal Bisnis teori dan Implementasi, 9(2):190-199

Pangesti, G.R., Tjahjono, H.K \& Maryati, T. (2013). The influence of transformational leadership, motivator factor, and hygiene factor toward job satisfaction of Balai Besar Latihan Ketransmigrasian Yogyakarta. Jurnal Bisnis Teori \& Implementasi. 4 (1), 31-44

Paschal, A. O., \& Nizam, I. (2016). Effects of Organisational Culture on Employees Performance : International Journal of Accounting and Business Management, 4(1), 9-26.

Tjahjono, H.K. (2004). Budaya Organisasional dan Balanced Scorecard: Dimensi Teori dan Praktik. UPFE UMY.

Tjahjono, H.K. (2005). Praktik-praktik manajemen SDM strategik: pengujian universalistik dan kontinjensi dalam menjelaskan kinerja organisasional. Jurnal Bisnis dan Ekonomi Kinerja, 9(2): 123-134.

Ubeda-garc1, M., Marco-Lajara, B., Sabater-Sempere, V., \& Garcia-Lillo, F. (2010). Does training influence organisational performance? European Journal of Training and Development, $37(4), 380-413$.

Zahriyah, U. W., Utami, H. nayati, \& Ruhana, I. (2015). Pengaruh Budaya Organisasional Terhadap Kinerja karyawan (Studi Pada Karyawan PT PLN (Persero) Distribusi jawa Timur Area Malang). Jurnal Administrasi Bisnis (JAB), 2(1), 1-7. 